\title{
Mortality structures population size characteristics of juvenile yellowtail kingfish Seriola lalandi reared at different densities
}

\author{
Damian Moran ${ }^{1, *}$, Cea K. Smith ${ }^{2}$, Peter S. Lee ${ }^{3}$, Stephen J. Pether ${ }^{2}$ \\ ${ }^{1}$ Department of Biology, Lund University, Sölvegatan 35, 22362 Lund, Sweden \\ ${ }^{2}$ National Institute of Water and Atmospheric Research Limited, Bream Bay Aquaculture Park, Ruakaka 0151, New Zealand \\ ${ }^{3}$ Department of Employment, Economic Development and Innovation, Bribie Island Research Centre, Woorim, \\ Queensland 4507, Australia
}

\begin{abstract}
A study was undertaken to measure the effects of conspecific density on the growth, mortality and deformity rate of yellowtail kingfish Seriola lalandi Valenciennes during the first feeding period. Newly hatched larvae were stocked in replicate tanks at initial densities of 40,60 and 100 ind. $\mathrm{l}^{-1}$ until $30 \mathrm{~d}$ post-hatch (DPH). Live prey was administered at frequent intervals in an effort to maintain absolute prey density for all treatments. There was a negative relationship between conspecific density and mean individual length during the first half of the trial, which was attributed to food depletion between supplementary feedings at higher conspecific densities. The effect size (partial eta-squared) of conspecific density decreased considerably during the trial, to the point where the initial stocking density had no discernible effect on cohort growth or mortality rate. The apparent morphological deformity rate ranged from 17 to $32 \%$, but did not differ between treatments. Jaw malformations were the most commonly observed deformity (12 to $30 \%$ ). The weights of juveniles at the end of the trial were log-normally distributed, with some disproportionately large individuals skewing the weight distributions. There was substantial variation in mortality between and within treatments (74 to $97 \%$ ), and the conspecific densities of each replicate at 30 DPH did not reflect the relative ordering of the initial treatments. Median individual weight was highly correlated with mortality and weight variance, and the positive skewness of populations decreased as mortality increased. Both trends indicated a strong population size-structuring mechanism. Given the controlled experimental conditions the size-structuring mechanism was not predation or cannibalism. Differential feeding success and an unidentified size-specific mortality agent are hypothesized to be the mechanisms by which mortality was able to strongly influence population size distributions.
\end{abstract}

KEY WORDS: Cohort size distribution - Deformity rate $\cdot$ Growth variation · Juvenile mortality Resale or republication not permitted without written consent of the publisher

\section{INTRODUCTION}

The yellowtail kingfish Seriola lalandi Valenciennes is a pelagic marine piscivore found in many parts of the Indo-Pacific (Nugroho et al. 2001), with a particularly high abundance near New Zealand (McGregor 1995). Despite the wide distribution of this species, relatively little is known about the early life history, mainly due to the fact that the spawning areas are not properly understood, and it is difficult to collect larvae and juve- niles from the open sea. The use of hatchery-reared juveniles to supply the yellowtail kingfish aquaculture industry in Australia, Japan and New Zealand has recently enabled researchers to investigate some aspects of the early life-history characteristics of this species (Carton 2005, Chen et al. 2007, Moran 2007, Moran \& Wells 2007, Moran et al. 2007a,b). As has been observed with larvae of other fish species, there is considerable inter- and intracohort variation in survival and growth during the early life stages of yellow- 
tail kingfish (Ebisu \& Tachihara 1993, Chen et al. 2006, Moran 2007). Conspecific density is an important factor in moderating growth and survival, because it affects the intensity of competition for food and shelter and also the degree of aggression and cannibalism (Smith \& Reay 1991, Hecht et al. 1996, Kestemont et al. 2003, Kotani et al. 2009). This is true both in the wild (Folkvord et al. 1994, Sakakura \& Tsukamoto 1996, Smith \& Fuiman 2003) and under the high-density conditions associated with aquaculture (Hecht \& Pienaar 1993). The current study evaluated the effects of conspecific density on the mortality, growth and size distribution of yellowtail kingfish during the first feeding period.

As is common for many marine fish species, considerable size heterogeneity develops during the first feeding phase in juvenile yellowtail kingfish, even in cohorts where the genetic parentage, age and larval hatch size are effectively identical and food is readily available (Ebisu \& Tachihara 1993, Moran 2007). A small proportion of large, fast-growing individuals significantly skews the size distributions of larval cohorts, and these large juveniles tend to be more aggressive and have higher survival, at least in an environment of plentiful food supply and no predation (Moran 2007). It is therefore necessary to analyse the size distribution to ensure that a meaningful measure of the central tendency for size is employed (i.e. median versus mean values) and appropriate statistical methods are used during comparisons. In addition, analysis of cohort size distribution can provide insights into size-dependent mortality and growth processes during the early lifehistory stages of fish (Folkvord et al. 2009). Folkvord and co-workers have employed cohort size distribution analysis to characterize the effects of temperature and prey concentration on the survival and growth of Atlantic cod Gadus morhua L. and herring Clupea harengus $\mathrm{L}$., and have been able to determine differences in growth strategies that are not apparent using traditional growth analyses dependent on summary statistics (reviewed in Folkvord et al. 2009). Analysis of the size distribution of juveniles in each replicate population was a particular focus of the current study.

The most commonly cited factors that give rise to size-dependent mortality of juvenile fish in the wild are predation and starvation resistance (Miller et al. 1988, Sogard 1997). In the present study, food was supplemented several times per day and predators were absent; therefore, it was assumed a priori that cohort growth and mortality characteristics would not be correlated with the size distribution. In addition to measuring the size and mortality characteristics of each cohort, developmental abnormalities were also recorded, as these are known to cause growth depression and high mortality rates in fish larvae (Cahu et al. 2003,
Verhaegen et al. 2007, Cobcroft \& Battaglene 2009) and are therefore an important covariate to consider in growth studies. The prevalence of abnormalities in the newly hatched larvae was not investigated prior to the experiment, as it is extremely difficult to assess skeletal deformation at this early developmental stage.

\section{MATERIALS AND METHODS}

Fish husbandry and experimental procedure. The trial was carried out at the National Institute of Water and Atmospheric Research Bream Bay Aquaculture Park in the north of New Zealand between November and December 2006. Yellowtail kingfish broodstock and egg incubation conditions were the same as those used by Moran et al. (2007a). Wild-caught broodstock spawned inside a $70 \mathrm{~m}^{3}$ tank following photothermal manipulation. The brood consisted of 15 fish, at least 5 of which were female. Previous research had shown that individual spawning events consisted of a single female and 1 or 2 males (Moran et al. 2007a). Floating eggs were collected from a spawning event shortly after fertilisation and incubated at $19.5^{\circ} \mathrm{C}$ in $400 \mathrm{l}$ conical fibreglass upwelling incubation tanks. All eggs were found to have a similar developmental stage (16 cells) when inspected, suggesting that the eggs were derived from a single spawning event and a single female. Larvae were transferred to the experimental larval rearing tanks at $1 \mathrm{~d}$ post-hatch (DPH).

The experimental treatments of initial larval stocking densities were set at 40,60 and 100 ind. $\mathrm{l}^{-1}$, with 3 replicates per treatment ( 9 tanks in total). In order to allocate the different densities to each replicate tank, the larvae in the egg incubators were concentrated into $10 \mathrm{l}$ volumes of water and the larval abundance estimated by 3 counts of larvae in a mixed $50 \mathrm{ml}$ subsample. The larvae were then randomly allocated to a trial tank, and this process was repeated until each tank had reached the required conspecific density. Efforts were made to ensure that the larvae were as evenly mixed as possible between the trial tanks, in order to minimise any bias in larval quality or abundance estimation that may have occurred during the concentration and counting of larvae from the egg incubators. The rearing tanks consisted of 9 black plastic $1500 \mathrm{l}$ upwelling tanks, with a side drain at the surface. Incoming water was at ambient temperature, $1 \mu \mathrm{m}$ filtered and UV treated. Each tank contained a central air stone, oxygen diffuser, outlet filter screen with air stone, overhead fluorescent light, surface skimmer and thermostatically controlled bar heater. Water temperature was initially the same as that used for egg incubation, but was increased at a rate of $1.0^{\circ} \mathrm{C}$ daily up to $24^{\circ} \mathrm{C}$. The tanks were initially maintained 
with low water flow $\left(0.25 \mathrm{l} \mathrm{min}^{-1}\right)$, but this was gradually increased to maintain water quality and oxygen levels at $>5 \mathrm{ppm}$. The larval and juvenile husbandry protocol followed that of commercial yellowtail kingfish production carried out at the site, but on a smaller scale. Approximately 2001 of the algae Nannochloropsis oculata was added daily until $18 \mathrm{DPH}$ to maintain a green water culture. Illumination was provided by a combination of diffuse sunlight and fluorescent lights run at the ambient photoperiod. Skimmers were cleaned 6 times daily from 3 to $8 \mathrm{DPH}$ to keep the tank surface clear of lipids and facilitate swim bladder inflation. After this time, skimmers were cleaned as required. Outlet filter screens were cleaned daily, and dissolved oxygen and temperature were recorded every morning and afternoon. Tank bottoms were siphoned to remove dead fish, uneaten food and detritus. The first siphon occurred at $6 \mathrm{DPH}$, and thereafter every 1 to $2 \mathrm{~d}$. Mortalities were either quantified by estimation of density in the collection bucket (in the case of larvae), or counted directly when fish were larger and mortalities not too numerous.

Best attempts were made to ensure that feed (both live prey and artificial feeds) were not a limiting factor. Rotifers Brachionus plicatilis were cultured and enriched using Culture Selco HD and Roti-Selco Alg (INVE), and were added 4 times per day (every 2 to $3 \mathrm{~h}$ between 08:00 and 17:00 h) from 3 to $19 \mathrm{DPH}$. Rotifer concentrations were maintained from 5 to 10 ind. $\mathrm{ml}^{-1}$ regardless of larval conspecific density. Artemia salina were enriched using Super Hufa (Salt Creek), and added from 13 to $29 \mathrm{DPH}$. The quantity of $A$. salina added was dependent on the remaining larval density and consumption rate, but was typically enough to allow a few $A$. salina to remain after $30 \mathrm{~min}$ of active feeding. A. salina were administered at the same frequency as rotifers. Artificial feeds (Gemma Micro 150300, Gemma 0.3 [Skretting], Proton 2-4 NRD 5/8 [INVE]) were added from $16 \mathrm{DPH}$ onwards, and gradually increased in particle size and quantity during the weaning process from live prey to artificial feed. The quantity of artificial feed administered was estimated according to consumption rate and juvenile density, but was typically fed to excess via continual addition from belt feeders. Any incidences of aiming, chasing, or cannibalistic behaviour that were observed during feeding and tank maintenance work were noted; however, there was no systematic schedule for behavioural observations. The reason for this was that an earlier study on the development of aggressive behaviour had shown that fin-nipping and cannibalism did not occur until 30 DPH onwards (Moran 2007).

The fish were raised until $30 \mathrm{DPH}$. Metamorphosis occurred at 20 to $23 \mathrm{DPH}$, at which point fish were termed juveniles. Growth rate was monitored by measuring the total length of 15 fish randomly sampled from each replicate tank every 3 to $4 \mathrm{~d}$ after the first day of feeding on Artemia salina (13 DPH). Total length $\left(L_{\mathrm{T}}\right)$ was measured under a dissecting microscope at $2 \times$ to $6 \times$ magnification to the nearest $0.1 \mathrm{~mm}$. Fish were not fed on the final day of the trial (30 DPH). Each tank was gently drained into a 751 bucket with a sieve to concentrate the juveniles into a smaller volume of water. After mixing the juveniles through the water column with a gentle swirling action, 100 fish were randomly sampled from each tank, dispatched via an overdose of anaesthetic (Aqui-S) and preserved in $10 \%$ seawater formalin. The blotted wet weight $\left(W_{\mathrm{W}}\right)$ of the fish was later measured to the nearest $1 \mathrm{mg}$ using a microbalance (Model WA205, Oertling), and total length was measured as previously described. All remaining fish in each tank were dispatched via anaesthesia and harvested into a large, fine-mesh net. The net was blotted dry from beneath, and the fish were transferred into a bucket to record biomass to the nearest $10 \mathrm{mg}$, which was later used in combination with average weights from the analysis of 100 individuals to quantify survival in each tank. A random sample of fish was also taken from each replicate and preserved in $10 \%$ seawater formalin to visually assess the deformity rate and type of 220 individuals at a later date. Deformities were categorized as jaw deformities (e.g. fused or asymmetrical jaw, shortened or extended upper or lower jaw), opercula deformities (e.g. flared or shortened operculum), spinal deformities (e.g. scoliosis or lordosis) and all other deformities. For any fish presenting multiple deformities, all relevant categories were recorded, although there were few such cases.

Statistical analyses. The first objective of the present study was to assess whether the conspecific density had an impact on mean $L_{T}$, survival and deformity rate. An initial analysis was done to check the suitability of the data set for parametric analysis. All statistical comparisons were performed in Statistica (V 8.0, StatSoft). Levene's tests showed that there were no significant differences in the homogeneity of variance of $L_{\mathrm{T}}$ amongst replicates at 13 and $16 \mathrm{DPH}$, but there were significant differences $(\mathrm{p}>0.05)$ at $21,24,28$ and $30 \mathrm{DPH}\left(F_{2,126}\right.$ values ranging from 2.29 to 4.81$)$. While the $F$-test in an analysis of variance (ANOVA) is relatively robust to deviations from normality and violations of the assumption of homogeneity of variance between groups (Lindman 1974), it can be misleading when group means are correlated with group variance. The means and variances of $L_{\mathrm{T}}$ were not correlated at 21, 24, 28 and $30 \mathrm{DPH}_{\text {; }}$ therefore, a nested ANOVA was considered suitable for statistical comparisons at each sampling point. As the analysis of the growth time series data involved using multiple ANOVA, a 
Bonferroni adjustment $(1 / \mathrm{n} \times \alpha, \alpha=0.05)$ was made to the $\alpha$-value so that differences were deemed statistically significant at $\mathrm{p}<0.008$. The partial eta-squared value (Pierce et al. 2004) was used to interpret the strength of the experimental factors (conspecific density and replicate) on the dependant variable $\left(L_{\mathrm{T}}\right)$.

The data from the measurement of 100 individuals per replicate for $W_{\mathrm{W}}$ and $L_{\mathrm{T}}$ at the completion of the trial were used to analyse the size distributions. A previous study showed that the size distribution of yellowtail kingfish juveniles can become particularly skewed around $30 \mathrm{DPH}$ and thereafter, with a small proportion of exceptionally large individuals in the population (Moran 2007). This meant the size distribution could not necessarily be assumed to be normally distributed, even with a sample size of 100 observations. The shape of the size distributions were characterized by the skewness (a measure of the asymmetry). The length and weight measurements from each replicate tank were modelled as a normal and log-normal distribution using the distribution fitting function in Statistica. A log-normal distribution has an elongated 'right-hand tail' to account for a small number of disproportionately large individuals. The goodness-of-fit of each distribution was evaluated by comparing the Chi-squared probability scores. A significant $p$-value $(\alpha$ level $=0.05)$ was interpreted to mean that the null hypothesis that the data come from a normal or log-normal distribution could be rejected. The arithmetic mean was used as an average for a normal distribution, and the median was used as an average for a log-normal distribution. The geometric mean could also be used as an appropriate average for individual weight in the latter case, as the population geometric mean is the population median for a log-normal distribution (Shih \& Binkowitz 1987). However, according to an analysis by Shih \& Binkowitz (1987), the sample median is a better measure of the average than the geometric mean at moderate sample sizes ( $\mathrm{n}=30$ to 50 ) for non-ideal log-normal distributions (i.e. contains outliers or observations from mixed distributions). Given that the individual weights analysed in the present study were not perfect lognormal distributions (see 'Results'), the median was deemed to be more appropriate than the geometric mean. The percent difference of the mean $(\bar{x})$ compared to the median $(\tilde{x})$ was used as a measure of how divergent the 2 averages were (calculated as $(1-\tilde{X} / \bar{X})$ $\times 100$ ).

In addition to calculating the mortality rate by the summation of the regular removal of dead individuals, the number of individuals surviving to $30 \mathrm{DPH}$ was calculated. Analysis of the size distribution showed that the median $W_{\mathrm{W}}$ was a more suitable measure of average weight than mean $W_{\mathrm{W}}$ (see 'Results'). Median $W_{\mathrm{W}}$ was used to calculate the number of fish surviving and the mortality rate by dividing the biomass weighed from each tank by the average weight of 100 individuals. Differences in the final mortality rate at $30 \mathrm{DPH}$ (as determined by the biomass method) amongst treatments were compared using ANOVA. The relationship between mortality, median weight and the degree of size variance (coefficient of variation of weight, $\mathrm{CV}_{W}=$ $\mathrm{SD} / \bar{X} \times 100)$ at the end of the trial was investigated using the 3-dimension correlation analysis in Statistica. The effect of mortality in shaping size distributions was investigated by plotting mortality against $W_{\mathrm{W}}$ skewness and by also testing whether there was a correlation between mortality rate and the top 5 and bottom 5 juvenile weights in each tank. The prevalence and type of deformity observed in each replicate tank at the end of the trial was converted to a percentage occurrence, which was then used to calculate a mean $( \pm \mathrm{SD})$ for each treatment. Differences in the prevalence of deformities between treatments were tested via ANOVA, and correlations with factors such as median weight and mortality were investigated.

\section{RESULTS}

Two trends were apparent in the growth of Seriola lalandi larvae stocked at different densities. First, at all sampling intervals, there was a significant effect of conspecific density on $L_{\mathrm{T}}$ over time (multiple 1-way ANOVA: $F_{2,6}=184.82$ to $\left.17.80, \mathrm{p}<0.001\right)$. There was a clear separation of mean $L_{\mathrm{T}}$ in each density treatment during the early parts of the trial, but this diminished over time (Fig. 1). The effect size (partial eta-squared) of conspecific density decreased from 0.75 at the first sampling interval to 0.22 by the end of the trial (Fig. 1). According to Cohen's (1992) interpretation of effect size magnitude, this means initial stocking density can be interpreted as having a strong effect on growth early in the trial, but only a small to moderate effect by the end of the trial. The relationship between conspecific density and growth was negative (Fig. 1), such that from 13 to $27 \mathrm{DPH}$ mean $L_{\mathrm{T}}$ values at 40 ind. $\mathrm{l}^{-1}$ were 4 to $7 \%$ greater than at 60 ind. $l^{-1}$ and 11 to $19 \%$ greater than at 100 ind. $\mathrm{l}^{-1}$. At $30 \mathrm{DPH}$ mean $L_{\mathrm{T}}$ was approximately equal for 60 and 100 ind. $\mathrm{l}^{-1}$ and $17 \%$ smaller than that for 40 ind. $\mathrm{l}^{-1}$.

The second trend apparent in the growth of larvae and juveniles over the trial was the considerable degree of variability in mean $L_{\mathrm{T}}$ between replicates, in particular during the latter parts of the trial. This was evident in the overlapping error bars in Fig. 1 and the increase in the $\mathrm{CV}$ of length $\left(\mathrm{CV}_{L}\right)$ from $3-7 \%$ at $13 \mathrm{DPH}$ to $10-17 \%$ at $30 \mathrm{DPH}$ (data not shown). The inter-replicate variability was significant (multiple 1way ANOVA: $F_{2,6}=22.0$ to $7.48, p<0.001$ ) for each 


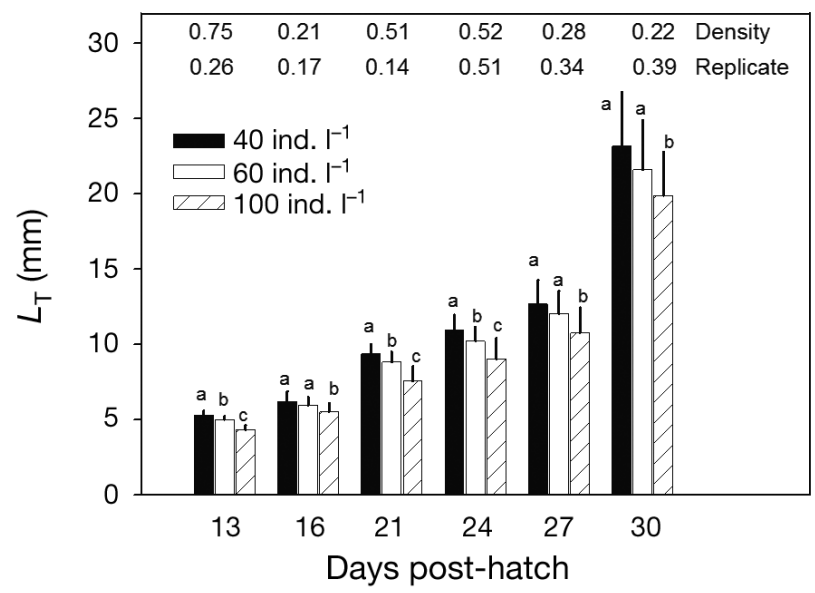

Fig. 1. Seriola lalandi. Change in mean total length, $L_{\mathrm{T}}( \pm \mathrm{SD})$, of larvae and juveniles at different initial conspecific densities (40, 60 and 100 ind. $^{-1}$ ). The effect size (partial eta-squared) of conspecific density and replicate variation is given above each sampling point. See 'Results' for ANOVA results. Each bar represents the mean $L_{\mathrm{T}}$ of the 45 larvae sampled per treatment; bars that share the same letter within each sampling day are not significantly different (Tukey's honestly significant difference test for treatment means, $p<0.05)$. Note: $x$-axis not to scale
The large degree of within-treatment variability that characterized the final average weight and length measurements (Fig. 2) was also evident in the number of larvae surviving in each tank. There was no significant difference in the number surviving amongst treatments as calculated by the final biomass method (ANOVA: $F_{2,6}=$ $0.86, \mathrm{p}=0.47$ ), with the range varying from 74 to $98 \%$ mortality. The mortality rate calculated by the summation of the almost daily removal of dead individuals considerably underestimated the mortality rate (range: 31 to $45 \%$; data not shown); however, this method was not as reliable as the former method because of problems with larvae degrading in the tank. The cumulative mortality data clearly showed that the majority of mortalities occurred between 1 and 15 DPH, when an estimated 500 to 15000 dead larvae were removed from each tank most days. After this time, most daily mortality was in the range of from 5 to 100 ind. $\mathrm{d}^{-1}$. The variable mortality experienced in each tank resulted in final stocking densities ( 1 to 19 ind. $\mathrm{l}^{-1}$ ) that were not only considerably lower than the initial densities $\left(40,60\right.$ and 100 ind. $\left.\mathrm{l}^{-1}\right)$, but also caused the relative density differences between treatments to diminish almost completely (Fig. 2). sampling period, and the effect size (partial eta-squared) increased over the course of the trial from 0.26 to 0.40 (Fig. 1). This indicates that, while the effect of within-treatment variability was smaller than the effect of conspecific density at the start of the trial, it came to represent a significant source of variation towards the end of the trial.

Analysis of the $L_{\mathrm{T}}$ data from each replicate tank at the end of the trial indicated that for 6 out of 9 replicate tanks either a normal or log-normal distribution provided an adequate model of the size distribution (Table 1). There was little difference between the mean and median values of $L_{\mathrm{T}}$ for each population, with the mean differing from the median by only -0.3 to $7 \%$ (Table 1). In comparison to the $L_{\mathrm{T}}$ distributions, the $W_{\mathrm{W}}$ distributions were considerably more skewed, with all distributions exhibiting a strong positive tendency (i.e. a long right tail). The influence of disproportionately large individuals was evident in the fact that the mean weight was 3 to $24 \%$ higher than the median, and $\mathrm{CV}_{W}$ was also approximately 3-fold that of $\mathrm{CV}_{L}$ for each replicate (Table 1).
Table 1. Seriola lalandi. Comparison of the length and weight distributions of each replicate tank at the end of the trial. The total length $\left(L_{\mathrm{T}}\right)$ and wet weight $\left(W_{\mathrm{W}}\right)$ measurements of 100 juveniles from each replicate were modelled as normal or log-normal distributions, and a Chi-squared probability score (p) was assigned to each distribution. The relative differences between quartiles and averages are presented along with the coefficient of variation $(\mathrm{CV}, \%)$. The relative interquartile range was calculated as $\left(Q_{3}-Q_{2}\right) /\left(Q_{2}-Q_{1}\right)$. Magnitude difference $(\%)$ of mean size $(\bar{x})$ compared to median size $(\tilde{X})$ was calculated as $(1-\bar{X} / \tilde{X}) \times 100 . \mathrm{CV}=\mathrm{SD} / \bar{X} \times 100$

\begin{tabular}{|c|c|c|c|c|c|c|c|}
\hline Density & Replicate & Skew & $\begin{array}{c}\mathrm{p} \\
\text { Normal }\end{array}$ & $\begin{array}{c}\text { p log- } \\
\text { normal }\end{array}$ & $\begin{array}{l}\text { Interquartile } \\
\text { range }\end{array}$ & $\begin{array}{l}\bar{X}: \tilde{X} \\
(\%)\end{array}$ & $\begin{array}{l}\mathrm{CV} \\
(\%)\end{array}$ \\
\hline \multicolumn{8}{|c|}{ Total length, $L_{\mathrm{T}}$} \\
\hline 40 & $\begin{array}{l}1 \\
2 \\
3\end{array}$ & $\begin{array}{r}-0.028 \\
0.391 \\
0.871\end{array}$ & $\begin{array}{l}0.63 \\
0.21 \\
0.02\end{array}$ & $\begin{array}{l}0.50 \\
0.16 \\
0.20\end{array}$ & $\begin{array}{l}1.15 \\
0.62 \\
0.90\end{array}$ & $\begin{array}{r}0.7 \\
-0.3 \\
2.9\end{array}$ & $\begin{array}{l}11 \\
10 \\
15\end{array}$ \\
\hline 60 & $\begin{array}{l}1 \\
2 \\
3\end{array}$ & $\begin{array}{l}0.651 \\
0.916 \\
1.126\end{array}$ & $\begin{aligned} & 0.01 \\
< & 0.01 \\
< & 0.01\end{aligned}$ & $\begin{array}{r}0.07 \\
<0.01 \\
<0.01\end{array}$ & $\begin{array}{l}1.97 \\
1.22 \\
2.96\end{array}$ & $\begin{array}{l}4.2 \\
4.9 \\
7.0\end{array}$ & $\begin{array}{l}14 \\
14 \\
18\end{array}$ \\
\hline 100 & $\begin{array}{l}1 \\
2 \\
3\end{array}$ & $\begin{array}{l}0.603 \\
0.655 \\
0.823\end{array}$ & $\begin{array}{r}0.10 \\
0.14 \\
<0.01\end{array}$ & $\begin{array}{r}0.19 \\
0.34 \\
<0.01\end{array}$ & $\begin{array}{l}3.21 \\
1.80 \\
1.27\end{array}$ & $\begin{array}{l}1.2 \\
1.0 \\
3.4\end{array}$ & $\begin{array}{l}13 \\
10 \\
16\end{array}$ \\
\hline \multicolumn{8}{|c|}{ Wet weight, $W_{W}$} \\
\hline 40 & $\begin{array}{l}1 \\
2 \\
3\end{array}$ & $\begin{array}{l}0.406 \\
0.932 \\
1.315\end{array}$ & $\begin{array}{r}0.06 \\
0.01 \\
<0.01\end{array}$ & $\begin{array}{l}0.10 \\
0.08 \\
0.01\end{array}$ & $\begin{array}{l}1.18 \\
1.85 \\
1.85\end{array}$ & $\begin{array}{r}3.4 \\
6.7 \\
15.2\end{array}$ & $\begin{array}{l}30 \\
31 \\
46\end{array}$ \\
\hline 60 & $\begin{array}{l}1 \\
2 \\
3\end{array}$ & $\begin{array}{l}1.122 \\
1.248 \\
1.579\end{array}$ & $\begin{array}{l}<0.01 \\
<0.01 \\
<0.01\end{array}$ & $\begin{array}{r}0.03 \\
<0.01 \\
<0.01\end{array}$ & $\begin{array}{l}2.29 \\
2.39 \\
3.30\end{array}$ & $\begin{array}{l}15.7 \\
15.1 \\
24.3\end{array}$ & $\begin{array}{l}42 \\
41 \\
55\end{array}$ \\
\hline 100 & $\begin{array}{l}1 \\
2 \\
3\end{array}$ & $\begin{array}{l}1.116 \\
1.208 \\
1.356\end{array}$ & $\begin{array}{l}<0.01 \\
<0.01 \\
<0.01\end{array}$ & $\begin{array}{l}0.31 \\
0.80 \\
0.15\end{array}$ & $\begin{array}{l}1.41 \\
1.06 \\
1.86\end{array}$ & $\begin{array}{r}10.2 \\
5.6 \\
13.1\end{array}$ & $\begin{array}{l}41 \\
32 \\
46\end{array}$ \\
\hline
\end{tabular}




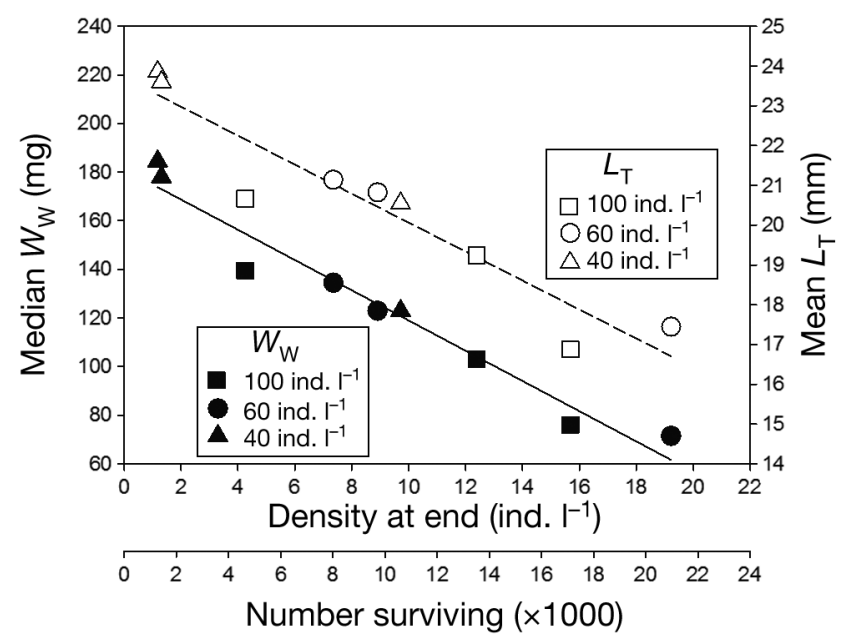

Fig. 2. Seriola lalandi. Relationship between final stocking densities and median wet weight ( $\left.W_{\mathrm{W}}\right)$ (closed symbols) and mean total length $\left(L_{\mathrm{T}}\right)$ (open symbols) of juveniles at the end of the trial. Note: the initial stocking density treatments changed considerably during the course of the trial due to differential mortality in each replicate tank

While the degree of mortality experienced within each replicate tank was not influenced by the density treatments, there was a clear correlation between the median weight of individuals in each cohort and the mortality and $\mathrm{CV}_{W}$ (Fig. 3a; multiple $\mathrm{R}^{2}(z / x y)=0.90$, $\mathrm{p}<0.01$ ). The relationship between median weight and mortality was strongly positive, such that a $10 \%$ increase in mortality rate was approximately equivalent to a 60 to $75 \%$ increase in median weight. The relationship between median weight and $\mathrm{CV}_{W}$ was strongly negative, whereby a $10 \%$ increase in $\mathrm{CV}_{W}$ was approximately equivalent to a $30 \%$ decrease in median weight. Another way of expressing these relationships is that tanks that experienced high mortality had high median weights and relatively low size variation, whereas tanks that experienced lower mortality had smaller median weights and greater size variation. This general relationship could be refined further by accounting for the effect initial stocking density had on average growth rates. When the size-mortality data were plotted according to treatment, the correlation coefficients were almost at unity for each stocking density (Fig. 3b), indicating the strength of the weightmortality correlation. The linear regression lines were spread according to the pattern evident in Fig. 1, namely that at higher initial stocking densities the average size tended to be smaller.

Analysis of the skewness of the $W_{\mathrm{W}}$ size distribution and mortality indicated that the higher the mortality rate for a tank, the lower the positive (right-hand) skewness (Fig. 4). There was no correlation between mortality rate and the top 5 juvenile weights recorded

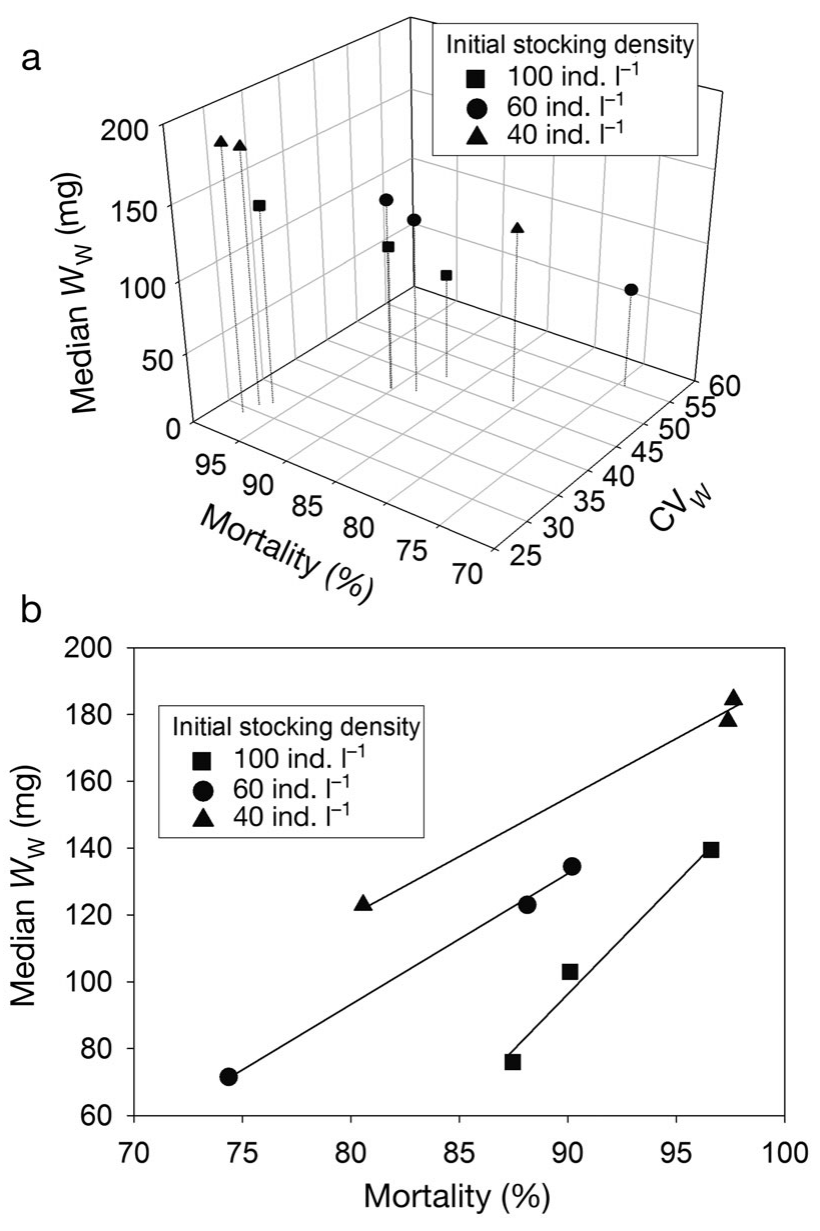

Fig. 3. Seriola lalandi. (a) Relationship between mortality, the coefficient of variation of weight $\left(\mathrm{CV}_{W}\right)$ and median wet weight $\left(W_{\mathrm{W}}\right)$ at the end of the trial. The linear regression statistics for the combined data set are: median $W_{\mathrm{W}}=1032.9-$ $5.9 \times \mathrm{CV}_{W}-9.5 \times$ mortality, multiple $\mathrm{R}^{2}(z / x y)=0.90, \mathrm{p}<0.01$. (b) Relationship between tank mortality rate and median weight of juveniles at the end of the trial. The linear regression statistics are, for 100 ind. $\mathrm{l}^{-1}: y=6.70 x-505.76, \mathrm{R}^{2}=0.98$; for 60 ind. $\mathrm{l}^{-1}: y=3.90 x-218.43, \mathrm{R}^{2}=0.99$; and for $40 \mathrm{ind} . \mathrm{l}^{-1}$ :

$$
y=3.44 x-154.33, \mathrm{R}^{2}=0.99
$$

in each tank $\left(\mathrm{R}^{2}=0.18, F_{1,7}=1.562, \mathrm{p}=0.252\right)$; however, there was a significant and positive correlation between mortality rate and the bottom 5 juvenile weights in each tank $\left(\mathrm{R}^{2}=0.52, F_{1,7}=7.662, \mathrm{p}=0.028\right)$.

In the latter period of the trial, at 20 to $30 \mathrm{DPH}$, some large individuals were observed 'J-posturing' towards conspecifics (described by Sakakura \& Tsukamoto 1996), and, in some instances, this was followed by chasing. No incidences of ingestion or cannibalism were observed.

The deformity rate observed in each replicate varied between 17 and $32 \%$, but there was no significant difference amongst treatments at the end of the trial (ANOVA: $F_{2,6}=2.0, \mathrm{p}=0.22$ ). The most prevalent type of deformity was jaw abnormalities, affecting from 12 


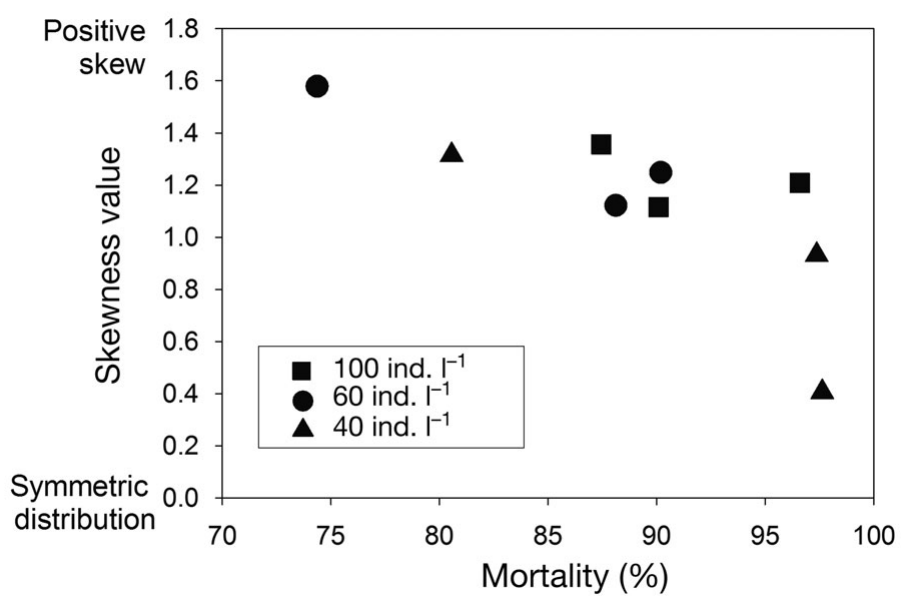

Fig. 4. Seriola lalandi. Comparison of mortality versus skewness of population wet weight for each replicate at the end of the trial

to $30 \%$ of the juveniles, while opercular deformities affected from 1 to $9 \%$ of the population. Externally, visible spinal deformities were uncommon (0.0 to $0.8 \%$ ), and there was no correlation between the deformity rate of fish in each tank and mortality, median $W_{\mathrm{W}}$ or $\mathrm{CV}_{W}\left(\mathrm{r}^{2}<0.3\right.$ for all correlations).

\section{DISCUSSION}

Increasing conspecific density was seen to have a negative effect on the growth rate of Seriola lalandi, especially during the first feeding period from 13 to $23 \mathrm{DPH}$. An obvious explanation for this would be differences in the availability of food. Efforts were made to maintain the relative availability of food by keeping the concentration of live and artificial feed similar for each replicate. The $L_{\mathrm{T}}$ gains observed amongst treatments suggest that the feeding rates must have been sufficiently fast to deplete the concentration of live prey between supplementary feedings to a point where maximum growth could not be attained at higher conspecific densities. There was no significant difference in the size of the 5 largest individuals sampled from each tank, implying that fast-growing individuals did equally well in all treatments. The slower growing individuals, which are assumed to have poorer food capture and processing capabilities, were most likely those most affected by the probable depletion of prey between supplementary feedings. Feed intake is not the only factor that could account for differences in growth. It is possible that at higher densities there were more social interactions, such as chasing; therefore, relative activity levels should also be considered. Conspecific density is known to affect the intensity of aggression (Smith \& Reay 1991, Kestemont et al. 2003); however, in yellowtail kingfish, the first chasing events are not observed until around $18 \mathrm{DPH}$ (Moran 2007). Therefore, it is unlikely that densitydependent aggression can account for differences in activity levels and growth rates during the first $10 \mathrm{~d}$ of the current study. It is more likely that the initial differences in growth rates between larval densities were attributable to lower prey abundances and increased foraging costs, which, in turn, resulted from densitydependent competition for prey.

Later in the trial the effect of conspecific density on $L_{\mathrm{T}}$ gain decreased, and there was large variation in the mean $L_{\mathrm{T}}$ of individuals amongst replicate tanks. The experimental treatments were not observed to have any effect on cohort mortality or size characteristics by 30 DPH. Baskerville-Bridges \& Kling (2000) published similar findings for Atlantic cod larvae reared over a range of densities (50 to 300 ind. $\mathrm{l}^{-1}$ ). Providing adequate prey quantities were given to prevent food from becoming a limiting factor, Atlantic cod rearing success was reported to be independent of initial stocking density. An important similarity between the current study and that of Baskerville-Bridges \& Kling (2000) was that the experiments were completed before cannibalism started, as cannibalism is known to be dependent on conspecific density in many fish species (Kestemont et al. 2003). Most studies investigating the effect of conspecific density include the cannibalism phase (e.g. Hecht et al. 1996, Sakakura et al. 1998, Baras et al. 2003, Fessehaye et al. 2006, Szkudlarek \& Zakęś 2007, Kotani et al. 2009); and therefore are not directly comparable with the present study.

The larval and juvenile mortality rates observed in the present study (approximately 5 to $12 \% \mathrm{~d}^{-1}$ ) were in the lower range of that reported to occur in the wild for marine pelagic fish (Houde 2002). At the end of the trial there was considerable variation in median weight and mortality within and between treatments, and the mortality rate was so variable that the relative density differences between treatments diminished completely. Despite a lack of any relationship between experimental treatment and mortality rate or median weight, there was a clear population structure amongst replicates. The final populations were generally characterized as having log-normal size distributions with a positive skew, meaning a small number of large individuals disproportionately affected the mean weight. There was a strong correlation between the mortality rate, median weight and weight variance in each cohort. Cohorts that experienced high mortality had high median weights and relatively low size variation, whereas those that experienced lower mortality had smaller median weights and larger size variation.

There are 2 possible mechanisms that could give rise to such strongly size-structured population statistics: 
differential feeding success following non-specific mortality and size-specific mortality. In the first scenario, elevated non-specific mortality in a population gives the remaining individuals better access to food, thereby reducing competition to the point where all individuals can attain maximum prey intake and growth, which, in turn, leads to higher average sizes and reduced size variance. Differential feeding success was the probable cause of the treatment growth differences early in the study, when prey availability was assumed to have been limiting to maximum growth in the higher density treatments (as discussed above). This mechanism is also assumed to be responsible for the treatment-specific stratification of the sizemortality data, as shown in Fig. 3b. However, differential feeding success is unlikely to be the sole causal agent for the relationship between mortality rate, median weight and population size variation, as grading trials of Seriola lalandi juveniles indicate that mortality is non-random, with smaller, slower growing individuals the most likely to suffer mortality (Moran 2007). In addition, slowly growing individuals reared in the absence of larger, aggressive conspecifics and which are provided with ample food do not gain more weight than similarly sized juveniles grown in a competitive environment (Moran 2007).

The second mechanism that could give rise to the observed relationship between mortality and various population statistics is size-specific mortality. If the mortality probability was negatively correlated with juvenile size at age (or more precisely juvenile 'growth potential'; sensu Folkvord et al. 2009), one would expect that with increasing population mortality there would be a correlated reduction in size skewness and $\mathrm{CV}_{W}$, increased median weight, decreased minimum individual weight and no effect on maximum individual weight. All the aforementioned correlations were observed in the current study. The data from the current study, combined with the findings of an earlier study on the growth potential of juvenile yellowtail kingfish (Moran 2007), suggest that there was a sizespecific mortality mechanism operating in conjunction with a differential feeding success mechanism.

While the initial differences in length gain between treatments can be explained by differential feeding success, there is no obvious size-selective mechanism that could have led to the mortality and population structure observed in the current study. The most commonly cited reasons for larval and juvenile mortality in the wild are starvation due to a lack of suitable prey and predation (reviewed in Houde 2002), and these factors are thought to strongly structure larval and juvenile survival at different sizes. Experimental studies that have analysed cohort size distribution under controlled conditions support starvation and predation as key size-structuring mechanisms. Rosenberg \& Haugen (1982) reared larval turbot Scophthalmus maximus Rafinesque in predator-free mesocosms and observed a correlation between mesocosm mortality rate and average size, which was interpreted to be a result of body-mass-dependent starvation resistance, as food was a limiting factor. As discussed earlier, the depletion of prey between supplementary feeding every 2 to $3 \mathrm{~h}$ probably reduced growth rates at the higher stocking densities, but the high frequency of feeding meant that starvation conditions were unlikely in the current study.

In the context of the current study, cannibalism is the only type of predation that needs to be considered as a mechanism that might structure mortality and fish size. Folkvord and co-workers have carried out several analyses of cohort size distribution during early development of Atlantic cod grown under controlled conditions, and have demonstrated that cannibalism modifies size distribution over time via the mortality of smaller individuals (Folkvord \& Otterå 1993, Folkvord 1997, Folkvord et al. 2009). No incidences of cannibalism were observed in the current study, which is in accordance with previous research for yellowtail kingfish reporting that cannibalism occurs from approximately 30 DPH onwards (Ebisu \& Tachihara 1993, Moran 2007). Chasing behaviour can occur before $30 \mathrm{DPH}$, and is mainly directed at smaller, slower growing individuals (Moran 2007), thereby representing a size-specific stressor that may increase mortality rate. However, many of the slow-growing juveniles are known to be on a degenerate developmental pathway irrespective of the aggressive environment (Moran 2007). Such a conclusion has also been reached by Letcher et al. (1996) using an individual-based modelling approach of larval fish survival. Given that mortality rates up to $30 \mathrm{DPH}$ were probably not a direct consequence of inter-individual aggression or food limitation, the mortality pattern observed in the current study must have had another causal basis, although there are no other obvious mechanisms of which we are aware. Transmissive diseases may play a role given that conspecific density is a key factor in disease prevalence; however, it is difficult to evaluate the relevance of this given the general lack of knowledge about the size-structuring effect of disease in larval and juvenile fish.

The visually determined deformity rate was not found to correlate with cohort mortality rate, average fish size, or size variance. Jaw malformations were the most prevalent deformity observed and were found to occur at a variable rate (12 to $30 \%$ ), as has been reported by Cobcroft et al. (2004) for yellowtail kingfish. Jaw malformations in fish are thought to have multiple aetiologies, including nutritional deficiencies, mechanical damage from feeding strikes at the tank 
wall (Cobcroft \& Battaglene 2009) and pollutants (Teraoka et al. 2006). Although vertebral deformities were rarely detected in the current study, these deformities are known to be difficult to determine via external visual inspection in recently metamorphosed juveniles, and may not be present as obvious deformities until fish are older (Witten et al. 2006).

From a larviculture perspective, the present study indicates that stocking density is an important covariate in modifying the population growth trajectories up

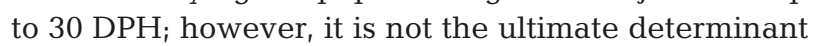
of population mortality or size distribution characteristics. When the current findings are viewed in a wider ecological context, they suggest that there may be an inherent population size-structuring mechanism for this species based on mortality that operates at a more fundamental level than the better understood prey size availability and predation mechanisms. These latter mechanisms may modify or magnify the effects of the putative inherent population size-structuring mechanism. The likely interaction of all of the aforementioned size-structuring mechanisms means future research examining this phenomenon will probably be restricted to laboratory- or mesocosm-scale experiments, where variables can be controlled.

Acknowledgements. We thank M. Wellenreuther for help in developing the manuscript and the staff at Bream Bay Aquaculture Park for their assistance in this study. This work was funded by the New Zealand Foundation for Research Science and Technology (Project No. C01X0301). D.M. was supported by the Foundation for Research, Science and Technology and a Marie Curie Postdoctoral Fellowship.

\section{LITERATURE CITED}

Baras E, Kestemont P, Melard C (2003) Effect of stocking density on the dynamics of cannibalism in sibling larvae of Perca fluviatilis under controlled conditions. Aquaculture 219:241-255

> Baskerville-Bridges B, Kling LJ (2000) Larval culture of Atlantic cod (Gadus morhua) at high stocking densities. Aquaculture 181:61-69

Cahu C, Zambonino Infante J, Takeuchi T (2003) Nutritional components affecting skeletal development in fish larvae. Aquaculture 227:245-258

Carton AG (2005) The impact of light intensity and algalinduced turbidity on first-feeding Seriola lalandi larvae. Aquacult Res 36:1588-1594

> Chen BN, Qin JG, Kumar MS, Hutchinson W, Clarke S (2006) Ontogenetic development of the digestive system in yellowtail kingfish Seriola lalandi larvae. Aquaculture 256: 489-501

> Chen BN, Qin JG, Carragher JF, Clarke SM, Kumar MS, Hutchinson WG (2007) Deleterious effects of food restrictions in yellowtail kingfish Seriola lalandi during early development. Aquaculture 271:326-335

> Cobcroft JM, Battaglene SC (2009) Jaw malformation in striped trumpeter Latris lineata larvae linked to walling behaviour and tank colour. Aquaculture 289:274-282
Cobcroft JM, Pankhurst PM, Poortenaar CW, Hickman B, Tait M (2004) Jaw malformation in cultured yellowtail kingfish (Seriola lalandi) larvae. NZ J Mar Freshw Res 38: $67-71$

Cohen J (1992) A power primer. Psychol Bull 112:155-159

Ebisu R, Tachihara K (1993) Mortality caused by cannibalism in seed production of gold striped amberjack Seriola lalandi. Bull Nagasaki Prefecture Inst Fish 19:1-7

Fessehaye Y, Kabir A, Bovenhuis H, Komen H (2006) Prediction of cannibalism in juvenile Oreochromis niloticus based on predator to prey weight ratio, and effects of age and stocking density. Aquaculture 255:314-322

Folkvord A (1997) Ontogeny of cannibalism in larval and juvenile fishes with special emphasis on Atlantic cod. In: Chambers RC, Trippel EA (eds) Early life history and recruitment in fish populations. Chapman \& Hall, London

Folkvord A, Otterå H (1993) Effects of initial size distribution, day length, and feeding frequency on growth, survival, and cannibalism in juvenile Atlantic cod (Gadus morhua L.). Aquaculture 114:243-260

Folkvord A, Øiestad V, Kvenseth PG (1994) Growth patterns of three cohorts of Atlantic cod larvae (Gadus morhua L.) studied in a macrocosm. ICES J Mar Sci 51:325-336

Folkvord A, Fiksen Ø, Høie H, Johannessen A, Otterlei E, Vollset KW (2009) What can size distributions within cohorts tell us about ecological processes in fish larvae? Sci Mar 73:119-130

Hecht T, Pienaar AG (1993) A review of cannibalism and its implications in fish larviculture. J World Aquacult Soc 24: 246-261

Hecht T, Battaglene S, Talbot B (1996) Effect of larval density and food availability on the behaviour of pre-metamorphosis snapper, Pagrus auratus (Sparidae). Mar Freshw Res 47:223-231

Houde ED (2002) Mortality. In: Fuiman LA, Werner RG (eds) Fishery science: the unique contributions of early life stages. Blackwell Science, Oxford

Kestemont P, Jourdan S, Houbart M, Melard C and others (2003) Size heterogeneity, cannibalism and competition in cultured predatory fish larvae: biotic and abiotic influences. Aquaculture 227:333-356

Kotani T, Wakiyama Y, Imoto T, Suzuki H, Fushimi H (2009) Effect of initial stocking density on larviculture performance of the ocellate puffer, Takifugu rubripes. J World Aquacult Soc 40:383-393

> Letcher BH, Rice JA, Crowder LB, Rose KA (1996) Variability in survival of larval fish: disentangling components with a generalized individual-based model. Can J Fish Aquat Sci 53:787-801

Lindman HR (1974) Analysis of variance in complex experimental designs. WH Freeman \& Co, San Francisco, CA

McGregor G (1995) Is the Northern Region the kingfish capital of the Pacific? Part 1: The fish. Seafood New Zealand 3: $28-30$

> Miller T, Crowder LB, Rice JA, Marshall EA (1988) Larval size and recruitment mechanisms in fishes: toward a conceptual framework. Can J Fish Aquat Sci 45:1657-1670

Moran D (2007) Size heterogeneity, growth potential and aggression in juvenile yellowtail kingfish (Seriola lalandi Valenciennes). Aquacult Res 38:1254-1264

> Moran D, Wells RMG (2007) Ontogenetic scaling of fish metabolism in the mouse-to-elephant mass magnitude range. Comp Biochem Physiol A 148:611-620

> Moran D, Smith CK, Gara BG, Poortenaar CW (2007a) Reproductive behaviour and egg development in yellowtail kingfish (Seriola lalandi Valenciennes, 1833). Aquaculture 262:95-104 
Moran D, Wells RMG, Gara BG (2007b) Energetics and metabolism of yellowtail kingfish (Seriola lalandi Valenciennes, 1833) during embryogenesis. Aquaculture 265:359-369

Nugroho E, Ferrell DJ, Smith P, Taniguchi N (2001) Genetic divergence of kingfish from Japan, Australia and New Zealand inferred by microsatellite DNA and mitochondrial DNA control region markers. Fish Sci 67:843-850

Pierce CA, Block RA, Aquinis H (2004) Cautionary note on publishing eta-squared values from multifactor ANOVA designs. Educ Psychol Meas 64:916-924

Rosenberg AA, Haugen AS (1982) Individual growth and size-selective mortality of larval turbot (Scophthalmus maximus) reared in enclosures. Mar Biol 72:73-77

Sakakura Y, Tsukamoto K (1996) Onset and development of cannibalistic behaviour in early life stages of yellowtail. J Fish Biol 48:16-29

Sakakura Y, Tagawa M, Tsukamoto K (1998) Whole-body cortisol concentrations and ontogeny of aggressive behavior in yellowtail (Seriola quinqueradiata Temminck and Schlegel: Carangidae). Gen Comp Endocrinol 109:286-292

Shih WJ, Binkowitz B (1987) Median versus geometric mean for lognormal samples. J Statist Comput Simulation 28: $81-83$

Editorial responsibility: Hans Heinrich Janssen, Oldendorf/Luhe, Germany
Smith ME, Fuiman LA (2003) Causes of growth depensation in red drum, Sciaenops ocellatus, larvae. Environ Biol Fishes 66:49-60

Smith C, Reay P (1991) Cannibalism in teleost fish. Rev Fish Biol Fish 1:41-64

Sogard SM (1997) Size-selective mortality in the juvenile stage of teleost fishes: a review. Bull Mar Sci 60:1129-1157

Szkudlarek M, Zakęś Z (2007) Effect of stocking density on survival and growth performance of pikeperch, Sander lucioperca (L.), larvae under controlled conditions. Aquacult Int 15:67-81

Teraoka H, Dong W, Okuhara Y, Iwasa H and others (2006) Impairment of lower jaw growth in developing zebrafish exposed to 2,3,7,8-tetrachlorodibenzo-p-dioxin and reduced hedgehog expression. Aquat Toxicol 78:103-113

> Verhaegen Y, Adriaens D, Wolf TD, Dhert P, Sorgeloos P (2007) Deformities in larval gilthead sea bream (Sparus aurata): a qualitative and quantitative analysis using geometric morphometrics. Aquaculture 268:156-168

> Witten PE, Obach A, Huysseune A, Baeverfjord G (2006) Vertebrae fusion in Atlantic salmon (Salmo salar): development, aggravation and pathways of containment. Aquaculture 258:164-172

Submitted: October 11, 2010; Accepted: December 20, 2010 Proofs received from author(s): January 19, 2011 